\title{
Exercise Rehabilitation After Stroke
}

\author{
Frederick M. Ivey, ${ }^{* \dagger+}$ Charlene E. Hafer-Macko, ${ }^{* \dagger+}$ and Richard F. Macko*t+ \\ *University of Maryland School of Medicine Departments of Medicine and Neurology and Divisions of Gerontology and \\ Rehabilitation Medicine, Baltimore, Maryland; 'Veterans Affairs Medical Center (VAMC) Geriatrics Research, Education, and \\ Clinical Center; ${ }^{\ddagger}$ VAMC Rehabilitation Research and Development Exercise and Robotics Center; and Stroke Research \\ Enhancement Program, Baltimore, Maryland
}

Summary: Stroke is a leading cause of disability that results not only in persistent neurological deficits, but also profound physical deconditioning that propagates disability and worsens cardiovascular risk. The potential for exercise-mediated adaptations to improve function, fitness, and cardiovascular health after stroke has been underestimated: it represents an emerging arena in neurotherapeutics. To define the health rationale for cardiovascular (aerobic) exercise, we first outline the impact of debilitating secondary biological changes in muscle and body composition on fitness and metabolic health after stroke. We provide an overview of evidence-based advances in exercise therapeutics, with a focus on task-oriented models that combine a progressive aerobic conditioning stimulus with motor learning to improve multiple physiological domains that determine longitudinal outcomes after stroke. Although progress in development of safe and effective exercise strategies is advancing, fundamental questions regarding dose intensity, prescription to optimize central and peripheral neuromuscular adaptations, and the public health value of exercise in secondary stroke prevention remain unanswered. Key issues steering future research in exercise neurotherapeutics are discussed within the context of initiatives to facilitate translation to community-based studies, requisite for dissemination. Key Words: Stroke, exercise, treadmill, rehabilitation, chronic disability.

\section{AEROBIC FITNESS AND FUNCTIONAL DECLINE AFTER STROKE}

Studies in stroke patients conducted in the early 1970s first reported that the energy requirements of hemiparetic gait were elevated by $55-100 \%$ compared with normal controls. ${ }^{1,2}$ Hemiparetic stroke patients were also observed as being unable to maintain their most efficient walking speed comfortably, indicating that poor endurance limited their functional mobility. ${ }^{1,3,4}$ During a 50yard ambulation task, elderly stroke patients demonstrated substantial activity intolerance, including dypsnea, progressive slowing, and worsened motor dexterity, which indicated that deconditioning limits ambulatory function and perhaps compromises gait safety. ${ }^{5}$ The detrimental combination of poor peak exercise capacity and elevated energy demands to perform routine ambulatory activities is termed diminished physiologic fitness reserve. ${ }^{6}$

Our findings in 131 chronic hemiparetic stroke pa-

Address correspondence and reprint requests to: Richard F. Macko, M.D., University of Maryland School of Medicine, Department of Neurology, 22 North Greene Street, Baltimore, MD 21201-1595. E-mail: rmacko@grecc.umaryland.edu. tients show a mean peak aerobic capacity $\left(\mathrm{VO}_{2 \text { peak }}\right)$ of $13.6 \pm 4(\mathrm{~mL} / \mathrm{kg}) / \mathrm{min}$ during progressive graded treadmill walking. ${ }^{7}$ This is similar to the baseline results of several previous studies investigating peak aerobic fitness levels after stroke (TABLE 1).

Age-matched individuals in their mid-60s who are physically inactive but otherwise healthy have peak oxygen consumption levels ranging between 25 and 30 $(\mathrm{mL} / \mathrm{kg}) / \mathrm{min} .{ }^{8,9}$ Thus, the peak oxygen consumption rate in our group of chronic stroke patients ${ }^{7}$ was roughly half that of age-matched controls.

These low $\mathrm{VO}_{2}$ peak levels compromise functional mobility after stroke and are near the minimum range required for basic activities of daily living. The human body at rest consumes roughly $3.5(\mathrm{~mL} / \mathrm{kg}) / \mathrm{min}$ of oxygen, or 1 metabolic equivalent (MET). ${ }^{10}$ The MET calculations associated with various forms of activity ${ }^{11}$ reveal that light instrumental activities of daily living (IADLs) generally require approximately 3 METS of oxygen consumption, whereas more strenuous ADLs require approximately 5 METS or $17.5(\mathrm{~mL} / \mathrm{kg}) / \mathrm{min}$. This contrasts with very intense forms of physical activity; running 6.0 miles per hour, for example, costs 10 METS or $35(\mathrm{~mL} / \mathrm{kg}) / \mathrm{min}$ for a person of normal body mass 
TABLE 1. Studies on Peak Aerobic Fitness after Stroke

\begin{tabular}{|c|c|c|c|}
\hline Study & Stroke Subjects & Testing Device & $\begin{array}{l}\text { Mean } \mathrm{VO}_{2} \text { Peak, } \\
(\mathrm{mLs} / \mathrm{kg}) / \mathrm{min}\end{array}$ \\
\hline Potempa et al., $1995^{1}$ & Chronic $(n=42), 43-72 \mathrm{yr}$ & Cycle ergometer & 15.9 \\
\hline Fujitani et al., $1999^{2}$ & $2-49 \mathrm{mo}$ after stroke $(n=30), 53.6 \mathrm{yr}$ & Cycle ergometer & 17.7 \\
\hline Rimmer et al., $2000^{3}$ & Chronic $(n=35), 53 \pm 8 \mathrm{yr}$ & Cycle ergometer & 13.3 \\
\hline Mackay-Lyons, $2002^{4}$ & Subacute $(n=29), 65 \pm 14 \mathrm{yr}$ & Treadmill 15\% BWS & 14.4 \\
\hline Duncan et al., $2003^{5}$ & Subacute $(n=92), 69 \pm 10 \mathrm{yr}$ & Cycle ergometer & 11.5 \\
\hline Kelly et al., $2003^{6}$ & Subacute $(n=17), 61 \pm 16 \mathrm{yr}$ & Semirecumbent cycle & 15.0 \\
\hline Chu et al., $2004^{7}$ & Chronic $(n=12), 62 \pm 9 \mathrm{yr}$ & Cycle ergometer & 17.2 \\
\hline
\end{tabular}

BWS = body weight supported.

index. Notably, published MET values for different activities do not take into account neurological disability, which may be associated with even higher energy requirements for gross motor activities due to biomechanical inefficiency.

A rather discouraging picture emerges regarding the peak oxygen consumption values of stroke patients relative to the range of energy expenditure necessary to perform daily activities (FIG. 1).

Whereas the normative peak values for age-matched healthy individuals exceed the approximate ADL range, the exhaustion value falls in the middle of the zone for the vast majority of stroke patients tested during treadmill walking in our lab (FIG. 1). ${ }^{7}$ Thus, many stroke patients must work to complete exhaustion just to achieve the middle of the established ADL range, making mid- to upper-level ADLs impossible or unsustainable. Many stroke survivors are functionally compromised on the basis of their peak oxygen consumption level. Even modest increases in the fitness levels of stroke patients could result in significant functional gains, enabling them to conduct ADLs below the anaerobic threshold. This supports a strong rationale for exercise-based interventions of sufficient intensity and duration to provoke adaptation in peak aerobic fitness.

\section{BIOLOGICAL MECHANISMS UNDERLYING POOR FITNESS AFTER STROKE}

Despite consensus that stroke leads to profound cardiovascular deconditioning, the underlying biological mechanisms have not been systematically investigated. The disability of stroke is widely attributed to brain injury alone, and the diminished cardiovascular fitness is speculated to be due to reduced central neural drive. There are, however, a number of major peripheral changes in skeletal muscle that could propagate disability and contribute to low fitness levels, including gross muscular atrophy, ${ }^{12}$ fiber phenotype shift, ${ }^{13}$ and associated insulin resistance. ${ }^{14}$ Here, we will briefly discuss these secondary biological abnormalities in skeletal mus- cle and body composition, and their clinical relevance as possible targets for therapeutic exercise after stroke.

\section{Gross tissue changes after stroke}

The amount of metabolically active tissue accounts in part for how much oxygen a person can utilize. Our studies in stroke confirm a strong relationship between thigh muscle mass, as measured by dual-energy X-ray absorptiometry (DEXA), and peak aerobic capacity. ${ }^{15}$ $\mathrm{VO}_{2}$ peak was related to the lean muscle mass of both thighs ( $r=0.64, p<0.001)$, with lean mass predicting $>40 \%$ of the variance in peak aerobic fitness. ${ }^{15} \mathrm{CT}$ scans of the paretic midthigh show $20 \%$ less muscle area than the nonparetic thigh $(p<0.0001)$. In addition, intramuscular fat is $25 \%$ greater in the paretic thigh than the nonparetic thigh $(p<0.0001) .{ }^{12}$ Elevated intramuscular fat may be associated with insulin resistance and its complications $^{12}$ and has relevance to cardiovascular fitness and function. ${ }^{15}$

\section{CHANGES IN TISSUE COMPOSITION AFTER STROKE}

Cellular changes in tissues of the paretic side may also contribute to poor fitness and worsening risk for cardio-

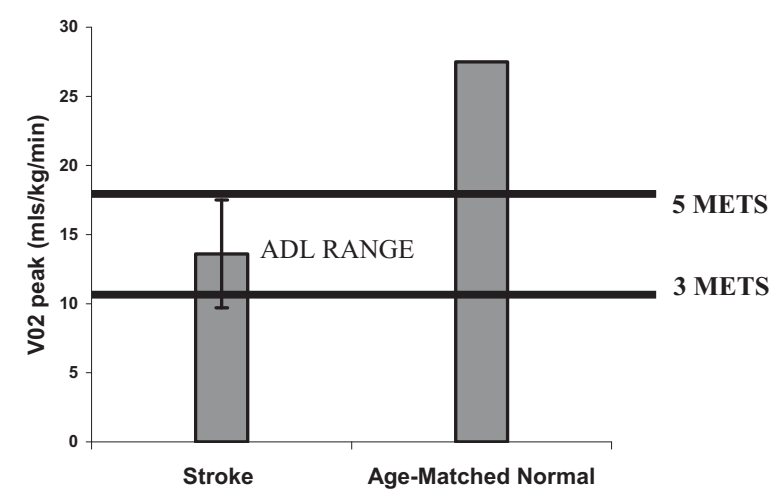

FIG. 1. Peak aerobic fitness levels (mean \pm SD) of chronic stroke patients $(n=131)$ relative to the energy requirements for activities of daily living (ADL). Error bars represent standard deviation. Reproduced with permission from Top Stroke Rehab (Ref. 7). 

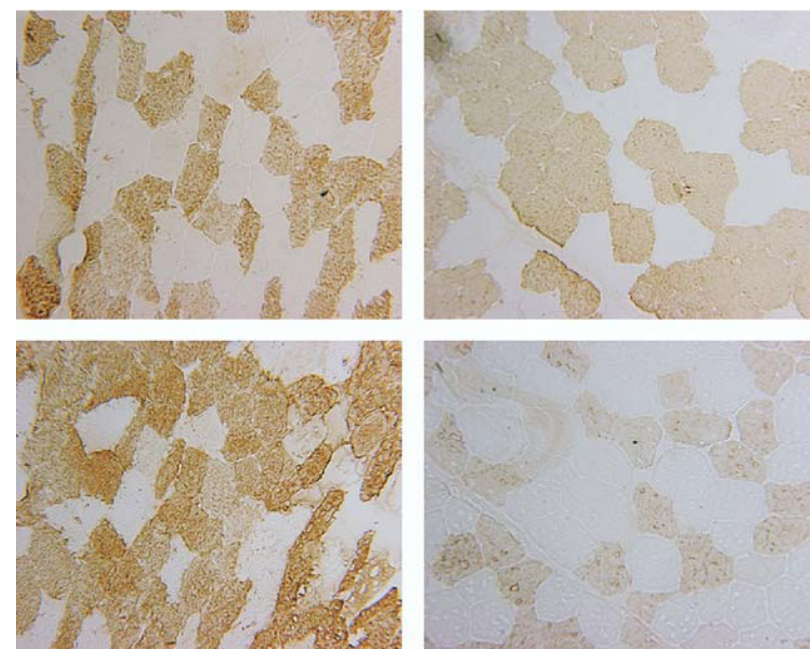

FIG. 2. There is a reduction in the percentage of slow myosin heavy chain (MHC) isoform fibers (Top images, brown fibers) and relative atrophy of the fast $\mathrm{MHC}$ isoform (Bottom images, brown fibers) in the paretic vastus lateralis (Left view) skeletal muscle, compared with normal mosaic equal distribution of slow and fast $\mathrm{MHC}$ isoform fibers in the nonparetic leg (Right view).

vascular disease. Routine ATPase staining at $\mathrm{pH} 4.6$ and myosin heavy chain (MHC) gel electrophoresis of paretic leg muscle biopsies in 13 stroke patients showed elevated proportions of fast type II fibers (FIG. 2). ${ }^{7}$

Further, densitometric analysis of MHC gel electrophoresis showed a significantly elevated proportion of fast MHC isoforms in the paretic $(68 \% \pm 14$, range $46-88 \%$ of total MHC) versus nonparetic leg $(50 \% \pm$ 13 , range $32-76 \%, p<0.005){ }^{13}$ These findings contrast with the relatively equal proportions of slow and fast MHC fibers found in the vastus lateralis of individuals without stroke. ${ }^{16}$ The shift to fast MHC in the stroke paretic leg muscle would be expected to result in a more fatigable muscle fiber type that would also be more insulin resistant. ${ }^{17}$ In the paretic limb only, the proportion of fast MHC isoform is strongly negatively related to self-selected walking speed $(r=$ $-0.78, p<0.005$ ), suggesting that neurological gait deficit severity may account for as much as $61 \%$ of the variance in fast $\mathrm{MHC}$ isoform. ${ }^{13}$ In our cohort, both muscular atrophy and the shift to the fast MHC isoform in the paretic limb are strong predictors of gait deficit severity. Hence, it is likely that the cellular composition of muscle tissues on the paretic side of the body in chronic stroke patients contributes to reduced $\mathrm{VO}_{2}$ peak levels, poor ambulatory function, and deteriorating whole-body metabolic status. This has major implications for overall cardiovascular risk and neurological function that could lead to new treatment strategies to improve skeletal muscle metabolism and contractile properties in this population.

\section{Inflammatory pathway activation after stroke}

The biological mechanisms underlying gross muscle atrophy and impaired metabolic function after hemiparetic stroke are not well understood. In non-neurological populations, increased skeletal muscle expression of tumor necrosis factor- $\alpha(\mathrm{TNF} \alpha)$, an inflammatory cytokine, is associated with sarcopenia in advancing age and models of disuse atrophy. ${ }^{18,19}$ Moreover, $\mathrm{TNF} \alpha$ has been linked to diabetes and the metabolic syndrome. ${ }^{20}$ This relationship between TNF $\alpha$ and diabetes is supported by the ability of $\mathrm{TNF} \alpha$ to block insulin signaling, which produces insulin resistance in vivo and is reversible by the administration of $\mathrm{TNF} \alpha$ receptor blocking agents. ${ }^{21} \mathrm{We}$ are therefore investigating inflammatory pathway activation in hemiparetic stroke muscle.

We recently reported increased levels of inflammatory cytokines in leg skeletal muscle of chronic hemiparetic patients $(n=29)$, compared with community controls without neurological disease or gait impairment $(n=9) .{ }^{22}$ Specifically, vastus lateralis muscle biopsy samples from the paretic limb had TNF $\alpha$ mRNA levels that were significantly higher than controls $(6.28 \pm 1.86$ versus $2.28 \pm$ $0.67, p<0.03)$. There was a trend toward elevated TNF $\alpha$ in paretic thigh, relative to nonparetic thigh $(3.71 \pm 1.02, p$ $=0.1$. Skeletal muscle TNF $\alpha$ mRNA levels were 2.8 -fold higher in paretic and 1.6-fold higher in nonparetic vastus lateralis, compared with controls (FIG. 3). ${ }^{22}$

In selected non-neurological disability populations, including frail elderly and individuals with heart failure, similar levels of elevated $\mathrm{TNF} \alpha$ expression were observed. Exercise training was able to reduce skeletal muscle TNF $\alpha$ expression enough to improve muscle protein and muscle strength. ${ }^{19}$ These studies support a rationale for further investigations of the effects of exercise to attenuate muscle inflammatory pathways and improve rehabilitation health outcomes after stroke.

\section{Hemodynamic changes after stroke}

Impaired paretic leg blood flow in chronic stroke may also contribute to exercise intolerance and low $\mathrm{VO}_{2}$ peak. We compared the resting calf blood flow in the paretic and nonparetic legs of 19 stroke patients by strain gauge plethysmography. ${ }^{23}$ This study revealed significant differences in resting calf blood flow between the paretic and nonparetic limbs: $2.3 \pm 0.2$ versus $3.4 \pm 0.2$ $(\mathrm{mL} / 100 \mathrm{~mL}) / \mathrm{min}(p<0.001)$. There was a $32 \%$ difference in resting blood flow between limbs. In addition, postischemic reactive hyperemic blood flow was $35 \%$ lower in the affected leg (13.5 \pm 1.6 versus $8.8 \pm 1.4, p$ $<0.001)$, suggesting reduced vasomotor reactivity. The difference in both resting and reactive blood flow between limbs remained significant after covarying for lower leg lean mass values $(p<0.05) .{ }^{23}$ Adequate blood flow to the periphery is critical for the effective oxygen extraction during physical work. Active muscles require 


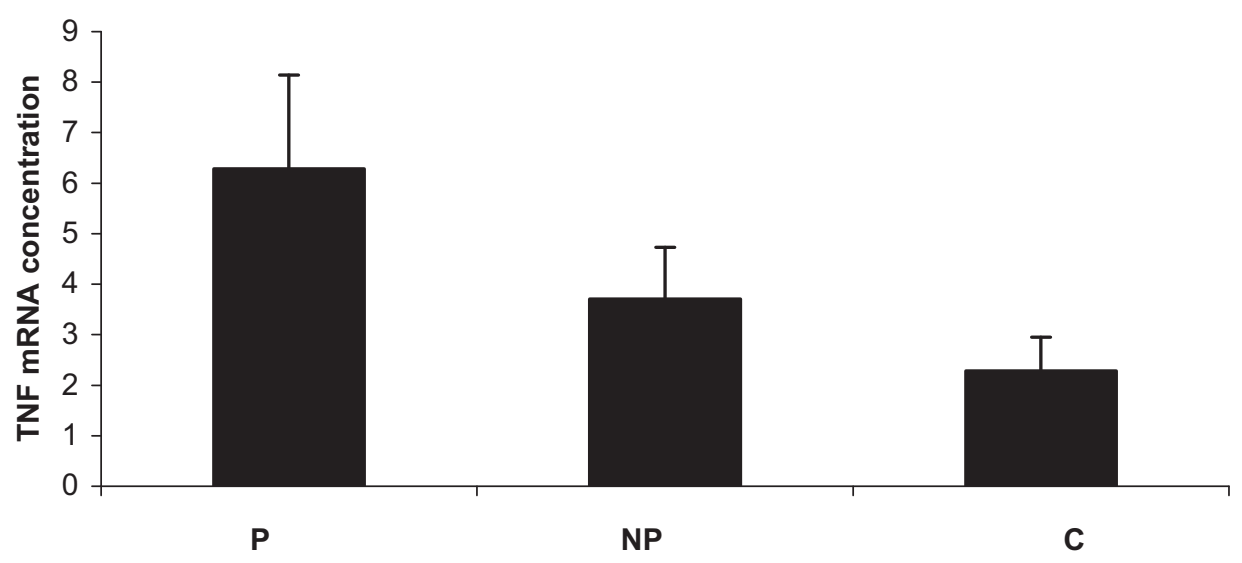

FIG. 3. Real-time reverse transcriptase PCR analysis of TNF $\alpha$ mRNA concentration (mean \pm SE) normalized against housekeeping gene in paretic (P) and nonparetic (NP) thigh after stroke and in control (C) muscle. Paretic thigh TNF $\alpha$ was significantly elevated, compared with control muscle $(p<0.03)$. Reproduced with permission from Stroke (Ref. 22).

proper access to oxygenated blood to efficiently utilize oxygen for energy production; reduced blood flow would compromise their ability to sustain physical activity. Thus, the hemodynamic change that accompanies hemiparesis may be clinically relevant to reduced $\mathrm{VO}_{2}$ peak levels and cardiovascular fitness.

\section{Impact of tissue-level changes on cardiovascular and metabolic risk}

The aforementioned poststroke changes in fitness and hemiparetic leg skeletal muscle and vascular tissue characteristics have potentially profound consequences for whole-body metabolic status (FIG. 4). Recent data show

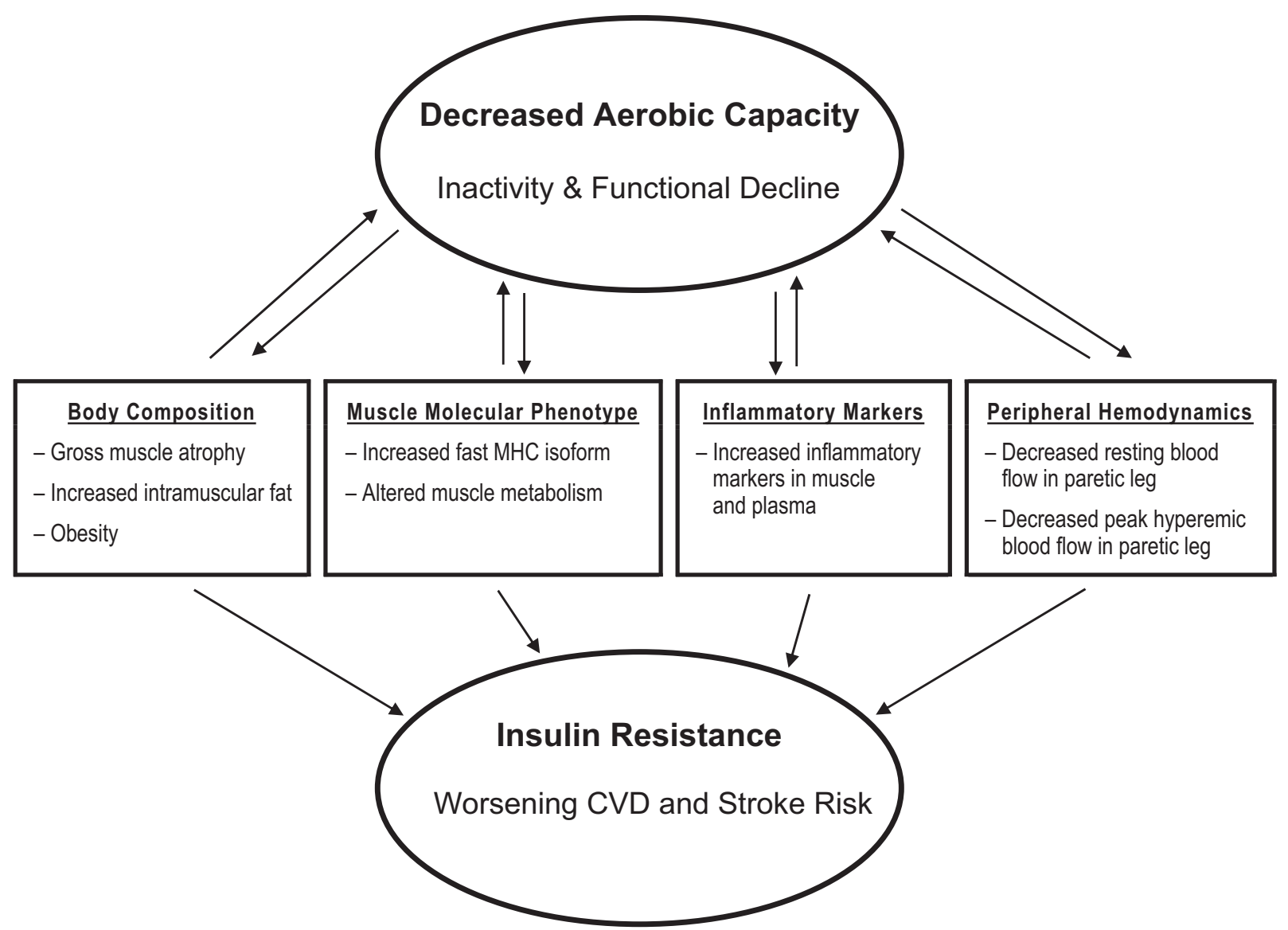

FIG. 4. Proposed conceptual model of tissue-level changes after stroke, with related functional and metabolic implications. CVD = cardiovascular disease; $\mathrm{MHC}=$ myosin heavy chain. 
TABLE 2. Exercise Interventions and Their Impact on Peak Aerobic Fitness: Six Studies

\begin{tabular}{|c|c|c|c|c|c|c|c|}
\hline \multirow[b]{2}{*}{ Study } & \multirow[b]{2}{*}{ Design } & \multirow{2}{*}{$\begin{array}{c}\text { Stroke } \\
\text { Population }\end{array}$} & \multicolumn{3}{|c|}{ Intervention } & \multicolumn{2}{|c|}{$\begin{array}{l}\text { Change in } \\
\mathrm{VO}_{2} \text { Peak }\end{array}$} \\
\hline & & & Duration & Treatment & Control & Tmt & Ctrl \\
\hline $\begin{array}{l}\text { Potempa et al., } \\
1995^{30}\end{array}$ & $\mathrm{RCT}$ & Chronic & $10 \mathrm{wk}$ & $\begin{array}{l}\text { Cycle training; } \\
3 \times \text { wk }\end{array}$ & $\begin{array}{l}\text { Passive range of } \\
\text { motion }\end{array}$ & $+13 \% *$ & $+1 \%$ \\
\hline$\underset{2000^{31}}{\text { Rimmer et al., }}$ & $\mathrm{RCT}$ & Chronic & $12 \mathrm{wk}$ & $\begin{array}{l}\text { Aerobic equipment } \\
\text { (30 min) and } \\
\text { strength equipment } \\
(20 \mathrm{~min}) ; 3 \times / \mathrm{wk}\end{array}$ & $\begin{array}{l}\text { Delayed entry } \\
\text { controls }\end{array}$ & $+8 \% *$ & $-10 \%$ \\
\hline $\begin{array}{l}\text { Macko et al., } \\
2001^{38}\end{array}$ & NonCtrl & Chronic & $6 \mathrm{mo}$ & $\begin{array}{l}\text { Treadmill exercise; } \\
3 \times / \mathrm{wk}\end{array}$ & - & $+10 \%{ }^{\dagger}$ & - \\
\hline $\begin{array}{l}\text { Duncan et al., } \\
2003^{27}\end{array}$ & RCT & Subacute & $12 \mathrm{wk}$ & $\begin{array}{l}\text { In-home, therapist- } \\
\text { supervised program } \\
\text { emphasizing } \\
\text { strength, balance, } \\
\text { endurance (cycle) }\end{array}$ & Usual care & $+9 \% *$ & $+1 \%$ \\
\hline $\begin{array}{l}\text { Chu et al., } \\
2004^{32}\end{array}$ & $\mathrm{RCT}$ & Chronic & $8 \mathrm{wk}$ & $\begin{array}{l}\text { Water-based aerobics, } \\
\leq 80 \% \text { HRR }\end{array}$ & $\begin{array}{l}\text { UE functional } \\
\text { exercise }\end{array}$ & $+23 \% *$ & $+3 \%$ \\
\hline $\begin{array}{l}\text { Macko et al., } \\
2005^{35}\end{array}$ & RCT & Chronic & $6 \mathrm{mo}$ & $\begin{array}{l}\text { Progressive treadmill } \\
\text { training; } 3 \times / \mathrm{wk}\end{array}$ & $\begin{array}{l}\text { Stretching (attention } \\
\text { controls) }\end{array}$ & $+17 \% *$ & $+3 \%$ \\
\hline $\begin{array}{l}\text { Pang et al., } \\
2005^{34}\end{array}$ & RCT & Chronic & 19 wk & $\begin{array}{l}\text { Community-based LE } \\
\text { exercise; } 3 \times / \mathrm{wk}\end{array}$ & $\begin{array}{l}\text { Community-based UE } \\
\text { exercise, seated }\end{array}$ & $+9 \% *$ & $+1 \%$ \\
\hline
\end{tabular}

$\mathrm{Ctrl}=$ control; $\mathrm{HRR}=$ heart rate reserve; $\mathrm{LE}=$ lower extremity, NonCtrl $=$ noncontrolled; $\mathrm{RCT}=$ randomized controlled trial; $\mathrm{Tmt}=$ treatment; UE $=$ upper extremity. * Significant between groups across time. ${ }^{\dagger}$ Significant within group.

that the prevalence of insulin resistance may be $>50 \%$ in nondiabetic individuals after stroke, ${ }^{14}$ and work from our group $^{24}$ showed that overall prevalence of abnormal glucose metabolism may be $>80 \%$ for individuals with chronic hemiparesis. Insulin resistance and associated hyperinsulinemia are linked to vascular and hemodynamic abnormalities, carotid-intima media thickening, and a prothrombotic environment conferring high population attributable risk for first stroke and myocardial infarction. ${ }^{24}$ Randomized studies are ongoing to determine whether treadmill exercise training can improve whole-body insulin and glucose metabolism in individuals with chronic hemiparesis.

\section{EFFICACY OF EXERCISE TRAINING AFTER STROKE}

Current rehabilitation models do not systematically provide adequate exercise to reverse the physical deconditioning, nor sufficient task repetition to optimize motor learning, nor maintenance exercise to sustain long-term health benefits after stroke. Conventional care is focused on the subacute period (i.e., initial 3 to 6 months) and is targeted toward recovery of ADL skills and basic mobility function. ${ }^{25}$ Cardiac monitoring reveals that $<3$ minutes in each typical physical therapy session reaches low aerobic intensity. ${ }^{26}$ Further, usual care for outpatient physical therapy, although quite variable in its application, was recently found to consist of only $9 \pm 5$ visits ending 30 to 180 days post stroke. ${ }^{27}$ These care models are reinforced by prospective studies that indicate recovery in ambulatory function and leg strength plateau within 3 months in $95 \%$ of cases. ${ }^{28}$ Most patients, however, are discharged without complete recovery, and nearly half decline in mobility function within a year, an outcome associated with earlier cessation of therapy. ${ }^{29}$ Novel exercise interventions that go beyond the subacute period are needed to realize the potential for long-term functional motor recovery and cardiovascular health in the chronic hemiparetic condition.

\section{Exercise training models}

Several exercise modalities have been proven to increase cardiovascular fitness in stroke survivors. A synthesis of these studies suggests that approaches to exercise training may necessarily vary as a function of neurological deficit severity, baseline fitness levels, and the time phase of recovery after stroke (TABLE 2). Moreover, differing elements of training prescriptions and their progression (e.g., aerobic intensity, training velocity, repetition) may further determine the nature of exercise-mediated outcomes, such as cardiovascular adaptations versus gains in locomotor function. We have summarized some of the more widely cited exercise intervention studies (from 1994 to 2006) that measured impact on peak aerobic capacity (TABLE 2 ) and functional outcomes (TABLE 3). The literature summarized in TABLES 2 and 3 provides strong evidence that several different exercise modalities can increase fitness levels and improve function after stroke. 
TABLE 3. Exercise Interventions and Their Impact on Selected Functional Outcomes: 13 Studies

\begin{tabular}{|c|c|c|c|c|c|c|c|c|}
\hline \multirow[b]{2}{*}{ Study } & \multirow[b]{2}{*}{ Design } & \multirow{2}{*}{$\begin{array}{c}\text { Stroke } \\
\text { Population }\end{array}$} & \multicolumn{3}{|c|}{ Intervention } & \multirow[b]{2}{*}{ Outcome measure } & \multicolumn{2}{|c|}{ Change in Function } \\
\hline & & & Duration & Treatment & Control & & Treatment & Control \\
\hline $\begin{array}{l}\text { Hesse et al., } \\
1994^{43}\end{array}$ & NonCtrl & $\begin{array}{l}\text { Subacute and } \\
\text { Chronic }\end{array}$ & $5 \mathrm{wk}$ & $\begin{array}{l}\text { Partial weight support } \\
\text { treadmill walking; } 5 \times / \mathrm{wk}\end{array}$ & - & $\begin{array}{l}\text { Rivermead Mobility Index; } \\
\text { Gait velocity }\end{array}$ & $\begin{array}{l}\text { RMI: }+110 \% \\
\text { GV: }+250 \%\end{array}$ & - \\
\hline Potempa et al., & $\mathrm{RCT}$ & Chronic & $10 \mathrm{wk}$ & Cycle training; $3 \times / \mathrm{wk}$ & $\begin{array}{l}\text { Passive range of } \\
\text { motion }\end{array}$ & Fugl-Meyer Index & No change & No change \\
\hline $\begin{array}{l}\text { Duncan et al., } \\
1998^{44}\end{array}$ & RCT & Subacute & $12 \mathrm{wk}$ & $\begin{array}{l}\text { Home-based: Theraband, } \\
\text { walking or bike for } 20 \\
\text { min }\end{array}$ & Usual care & $\begin{array}{l}\text { 10-m gait velocity; } \\
\text { 6-min walk distance }\end{array}$ & $\begin{array}{l}\text { GV: }+37.3 \% \\
\text { WD: }+28 \%\end{array}$ & $\begin{array}{l}\text { GV: }+12.3 \% \\
\text { WD: }+17 \%\end{array}$ \\
\hline $\begin{array}{l}\text { Teixeira-Salmela } \\
\text { et al } 1999^{45}\end{array}$ & NonCtrl & Chronic & $10 \mathrm{wk}$ & $\begin{array}{l}\text { Aerobic + strength training; } \\
3 \times / \mathrm{wk}\end{array}$ & & 30-m gait velocity & $+21.2 \% *$ & - \\
\hline $\begin{array}{l}\text { Rimmer et al., } \\
2000^{31}\end{array}$ & RCT & Chronic & $12 \mathrm{wk}$ & $\begin{array}{l}\text { A variety of aerobic ( } 30 \\
\text { min) and strength } \\
\text { equipment }(20 \mathrm{~min}) \\
3 \times / \text { wk }\end{array}$ & Delayed entry controls & Exercise time & $+29 \%$ & $+15 \%$ \\
\hline $\begin{array}{l}\text { Katz-Leurer } \\
\text { et al., } 2003^{46}\end{array}$ & RCT & Acute stroke & $8 \mathrm{wk}$ & $\begin{array}{l}\text { Cycle ergometer, } 60 \% \\
\text { HRR; } 2 \times / \mathrm{wk}\end{array}$ & Usual care & Post-intervention walk distance & WD: $143 \mathrm{~m}$ & WD: $108 \mathrm{~m}$ \\
\hline $\begin{array}{l}\text { Eng et al. } \\
2003^{47}\end{array}$ & NonCtrl & Chronic & $8 \mathrm{wk}$ & $\begin{array}{l}\text { Community-based aerobic } \\
\text { stepping, stretching, } \\
\text { functional LE } \\
\text { strengthening (chair rise); } \\
3 \times / \text { wk }\end{array}$ & - & $\begin{array}{l}\text { 12-min walk distance; } \\
10 \text {-m gait velocity }\end{array}$ & $\begin{array}{l}\text { WD: }+9.5 \% \\
\text { GV self-selected: }+14.4 \% \\
\text { GV fastest comfortable: }+9.3 \%\end{array}$ & - \\
\hline $\begin{array}{l}\text { Duncan et al., } \\
2003^{27}\end{array}$ & RCT & Subacute & $12 \mathrm{wk}$ & $\begin{array}{l}\text { In-home, therapist- } \\
\text { supervised program } \\
\text { emphasizing strength, } \\
\text { balance, endurance } \\
\text { (cycle) }\end{array}$ & Usual care & $\begin{array}{l}\text { 10-m gait velocity; } \\
\text { 6-min walk distance }\end{array}$ & $\begin{array}{l}\text { GV: }+25.7 \% \\
\text { WD: }+25.8 \%\end{array}$ & $\begin{array}{l}\text { GV: }+18 \% \\
\text { WD: }+15 \%\end{array}$ \\
\hline $\begin{array}{l}\text { Chu et al., } \\
2004^{32}\end{array}$ & RCT & Chronic & $8 \mathrm{wk}$ & $\begin{array}{l}\text { Water-based aerobics, } \\
\leq 80 \% \text { HRR }\end{array}$ & UE functional exercise & Self-selected gait velocity & $+16.1 \%$ & $+2.9 \%$ \\
\hline $\begin{array}{l}\text { Eich et al. } \\
2004^{48}\end{array}$ & RCT & Subacute & $6 \mathrm{wk}$ & $\begin{array}{l}\text { Harness-secured and } \\
\text { minimally supported } \\
\text { treadmill walking ( } 30 \\
\text { min) plus physiotherapy } \\
(30 \mathrm{~min}) ; 5 \times / \mathrm{wk}\end{array}$ & $\begin{array}{l}\text { Physiotherapy alone } \\
\quad(60 \mathrm{~min})\end{array}$ & $\begin{array}{l}\text { 10-m gait velocity (GV); } \\
\text { 6-min walk distance (WD) }\end{array}$ & $\begin{array}{l}\text { GV: }+78 \% \\
\text { WD: }+84 \%\end{array}$ & $\begin{array}{l}\text { GV: }+36 \% \\
\text { WD: }+51 \%\end{array}$ \\
\hline $\begin{array}{l}\text { Macko et al., } \\
2005^{35}\end{array}$ & $\mathrm{RCT}$ & Chronic & $6 \mathrm{mo}$ & $\begin{array}{l}\text { Progressive treadmill } \\
\text { training; } 3 \times / \mathrm{wk}\end{array}$ & $\begin{array}{l}\text { Stretching (attention } \\
\text { controls) }\end{array}$ & $\begin{array}{l}\text { 6-min walk distance (WD); } \\
\text { WIQ distance }\end{array}$ & $\begin{array}{l}\text { WD: }+30 \% \\
\text { WIQ: }+56 \%\end{array}$ & $\begin{array}{l}\text { WD: }+11 \% \\
\text { WIQ: }+12 \%\end{array}$ \\
\hline $\begin{array}{l}\text { Pang et al., } \\
2005^{34}\end{array}$ & $\mathrm{RCT}$ & Chronic & $19 \mathrm{wk}$ & $\begin{array}{l}\text { Community-based LE } \\
\text { exercise; } 3 \times / \mathrm{wk}\end{array}$ & $\begin{array}{l}\text { Community-based UE } \\
\text { exercise }\end{array}$ & 6-min walk distance (WD) & WD: $+19.7 \%$ & WD: $+12 \%$ \\
\hline $\begin{array}{l}\text { Pang et al., } \\
2006^{33}\end{array}$ & $\mathrm{RCT}$ & Chronic & 19 wk & $\begin{array}{l}\text { Community-based UE } \\
\text { exercise; } 3 \times / \mathrm{wk}\end{array}$ & $\begin{array}{l}\text { Community-based LE } \\
\text { exercise }\end{array}$ & $\begin{array}{l}\text { Wolf Motor Function test; } \\
\text { Fugl-Meyer assessment; } \\
\text { dynamometry grip strength }\end{array}$ & $\begin{array}{l}\text { UE: } 7 \% \\
\text { UE: } 12 \% \\
\text { UE: } 17 \%\end{array}$ & $\begin{array}{l}\text { WMF LE: } 0 \% \\
\text { Fugl-Meyer LE: } 2 \% \\
\text { GS LE: } 2 \%\end{array}$ \\
\hline
\end{tabular}

$\mathrm{GS}=$ grip strength $; \mathrm{GV}=$ gait velocity; $\mathrm{LE}=$ lower extremity; NonCtrl = noncontrolled; RCT = randomized controlled trial; $\mathrm{RMI}=$ rivermead mobility index; $\mathrm{SC}=$ stair climbing; $\mathrm{UE}=$ upper extremity; $\mathrm{WD}=$ walking distance; $\mathrm{WIQ}=$ walking impairment questionnaire; $\mathrm{WMF}=$ Wolf motor function test. 
Potempa et al. $^{30}$ are generally credited for the first randomized exercise trial involving hemiparetic stroke patients. The study compared 10 weeks of adapted bicycle ergometer exercise with a control intervention consisting of passive range of motion exercise. Results showed a significant between-group difference in $\mathrm{VO}_{2}$ peak change over time, with the bicycle ergometer group $(n=19)$ achieving 13\% gains, compared with no change for controls $(n=23)$. Though Fugl-Meyer sensorimotor scores were positively correlated with gains in peak $\mathrm{VO}_{2}$, neither of the treatment groups showed significant differences in functional outcome scores. This seminal study showed that aerobic exercise using cycle ergometry is feasible and improves fitness in chronic hemiparetic stroke, but provided no clear evidence that cycle exercise could improve neuromuscular function or functional mobility.

A subsequent intervention trial conducted by Rimmer et. al. ${ }^{31}$ involved primarily African-American stroke survivors and was multimodal with respect to the exercise intervention. A delayed-entry controlled design was used to provide training to all 35 participants. Outcome testing included measures of peak $\mathrm{VO}_{2}$, strength, flexibility, and body composition. The training protocol consisted of the following components, 3 times per week: cardiovascular endurance (30 minutes), muscle strength and endurance (20 minutes), and flexibility (10 minutes). Participants completed cardiovascular endurance training on one or more of the following machines: recumbent stepper, upright stepper, stationary cycle (recumbent and upright), treadmill, and elliptical cross-trainer. Participants also completed one set on a variety of upper- and lower-body strength training machines starting at $70 \%$ of the 10 repetition maximum weight (10RM) and progressing as they became stronger. Finally, a variety of upper- and lower-body stretching exercises were performed at various times throughout each 1 hour session. Results showed significant time $\times$ group interactions for the following measures during cycle ergometer fitness testing: $\mathrm{VO}_{2}$ peak, time to exhaustion, and maximal workload. Although the relative gains in $\mathrm{VO}_{2}$ peak were not as large as those previously demonstrated by Potempa et al., ${ }^{30}$ this may have been in part a function of the multiple training modalities used, perhaps resulting in a deemphasis on the intensity of aerobic training needed for gains in peak aerobic capacity. This was, however, the first randomized exercise study in stroke to show significant between-group effects for muscular strength and endurance, as well as improvement in body composition in terms of body weight, body mass index, and total skinfolds. ${ }^{31}$

Duncan et al. ${ }^{27}$ conducted the first of the randomized studies to apply a home-based intervention model. The program consisted of 36 sessions of 90 minutes duration over 12 to 14 weeks. Subjects in the usual-care group had services as prescribed by their physicians. All sessions for the exercise group were supervised by a physical or occupational therapist at home. Components of the program were range of motion and flexibility, strengthening, balance, upper-extremity functional use, and endurance training (riding a stationary bike for 30 minutes). Both the intervention and usual-care groups improved in strength, balance, upper- and lower-extremity motor control, upper-extremity function, and gait velocity. Gains for the intervention group exceeded those in the usualcare group in balance, endurance, peak aerobic capacity, and mobility. The study was important in demonstrating the practical utility of home-based interventions, compared to the more frequently applied hospital-based intervention programs for improving fitness and function after stroke. Note, however, that there was still a high level of supervision even though the study was homebased.

Chu et al. ${ }^{32}$ conducted a water-based exercise study lasting 12 weeks. Those in the experimental group exercised in a swimming pool for 1 hour, 3 times per week. The patients were progressed to 30 minutes of water aerobics at $80 \%$ heart rate reserve, with the remainder of the time devoted to stretching, warm-up, and cooling down. Although this study had a very small sample size (7 treatment subjects and 5 controls), the intervention produced the greatest relative gains in peak aerobic capacity shown to date (23\%), perhaps arguing for strong consideration of this form of intervention for stroke survivors. A higher level of baseline fitness and function may have influenced results and confounded interpretation relative to other experiments in the field of poststroke exercise rehabilitation.

Pang et al. ${ }^{33,34}$ assessed the effects of communitybased upper- and lower-extremity exercise programs on functional outcomes in persons with chronic stroke. Sixty-three stroke survivors were randomized to either an arm exercise group or a leg exercise group. Participants in both groups exercised for 19 weeks (1 hour sessions, 3 times per week). Sessions took place in a community hall setting and were supervised by a physical therapist, an occupational therapist, and an exercise instructor. The upper-extremity program consisted of shoulder exercises (Theraband), elbow and wrist weightbearing exercises (dumbbell and wrist cuff), and hand activities or functional training (playing cards, fine motor skills, electric stimulation to wrist extensors). Lowerextremity trainers trained for cardiorespiratory fitness and mobility with brisk walking, sit-to-stand exercises, walking through an obstacle course, and standing on a balance disk or wobble board. The lower-extremity group also engaged in partial squats and toe rises to improve muscle strength. Multivariate analysis on motor function and functional activity performance outcomes showed a significant group $\times$ time interaction, indicating 
that, overall, the arm group had significantly more improvement than the leg group with respect to selected functional outcomes (TABLE 3). ${ }^{33}$ The amount of improvement was comparable to other novel treatment approaches, such as constraint-induced movement therapy. Participants with moderate arm impairment benefited more from the upper-extremity program. The lower-extremity program was more effective for producing change in $\mathrm{VO}_{2}$ peak and 6-minute walk distance as shown in TABLES 2 and 3.

These randomized studies have established the efficacy of exercise to improve fitness and selected functional motor outcomes after stroke; however, the diversity of intervention design, heterogeneity in patient deficit profile, and timing of initiating therapy preclude consensus regarding the optimal training paradigms and parameters of exercise progression that are needed to improve outcomes in stroke survivors. Further research is needed to define how to best implement exercise rehabilitation across the spectrum of stroke deficit severity and phases of recovery. Whether neurological deficit profiles, baseline fitness levels, or advancing age influence the ability to respond to exercise treatment is unknown. Important questions remain regarding whether specific components of the training prescription such as exercise intensity, duration, and their progression influence the nature or temporal profile of exercise-mediated gains in cardiovascular and metabolic fitness or locomotor recovery after stroke. Treadmill training paradigms allow precise regulation of the locomotor training stimulus, aerobic training intensity, and progression.

In the remaining sections we summarize our progress investigating task-oriented treadmill aerobic training in chronic stroke patients and begin to address basic questions related to the influence of subtle manipulation of training parameters on specific mobility and fitness outcomes.

\section{Task-oriented training: merging models of motor learning with aerobic exercise}

We have emphasized full body-weight-support treadmill exercise as a model of task-oriented exercise that provides locomotor training according to a progressive aerobic exercise formula. ${ }^{35-38}$ The task-oriented exercise model assumes that multiple physiological systems (including CNS locomotor control, cardiovascular fitness, muscle structure, and metabolic health) are integral to improving mobility recovery and optimizing cardiovascular health and function.

The studies focus on individuals with chronic hemiparesis ( $>6$ months) who have already completed all conventional rehabilitation care. This strategy minimizes the potential confounding effects of early natural heterogeneous neurological recovery and intercurrent conventional care. Because neuroplasticity associated with motor learning and functional improvements is demonstrable in the chronic phases of stroke, this initial approach is proposed to best define the most effective motor learning regimens, which can then later be tested across the continuum of care. Because the temporal profile of exercise-mediated adaptations after stroke is unknown, we investigated 6-month progressive training, a much longer time window than is typical for neurorehabilitation care.

The treadmill training model leverages three physiologic principles: (a) improved reflexive gait patterning attributed to altered afferent proprioceptive input; (b) augmentation of locomotor entrainment with task repetition (which animal and human studies show is crucial for motor learning), and (c) progression of the metabolic demands of exercise training through increasing velocity, training session duration, and total program length.

The principle of progression raises fundamental questions regarding which exercise formulas are needed to improve functional and metabolic health outcomes. The following section provides evidence that biomechanical facilitation and short-term neural adaptations to paretic lower-extremity muscles are produced by the treadmill walking condition, and that specific elements of the training progression predict treatment outcome response.

\section{Treadmill training and gait patterning after stroke}

The biomechanical facilitation of hemiparetic gait symmetry is robust, and is associated with improved leg muscle activation patterns. We compared gait temporal and force parameters over ground to treadmill walking at matched velocities in untrained hemiparetic patients and found $50 \%$ improvement in interlimb stance-to-swing ratios, 30\% improvement in impulse symmetry, and $40 \%$ reduction in stride-to-stride variability. ${ }^{39}$ Treadmill walking also induces immediate changes in quadriceps activation patterns that parallel increased symmetry in gait patterning. ${ }^{40}$ Thus, treadmill training does not simply produce a mechanical facilitation, but also improves phasing of quadriceps activation, supporting a neurophysiologic rationale for treadmill to promote locomotor learning after stroke.

Using transcranial magnetic stimulation (TMS), we showed that corticospinal excitability to paretic quadriceps muscles of chronic hemiparetic stroke patients is increased by a single treadmill exercise training session. ${ }^{41}$ After initial assessment with TMS to quantify motor-evoked potential (MEP) responses to paretic and nonparetic quadriceps, participants treadmill walked for 20 minutes, simulating a single aerobic training session. We found that MEP amplitudes increased to paretic quadriceps muscles (but not the nonparetic side) in individuals who had participated in at least 3 months of regular treadmill training. ${ }^{41}$ 


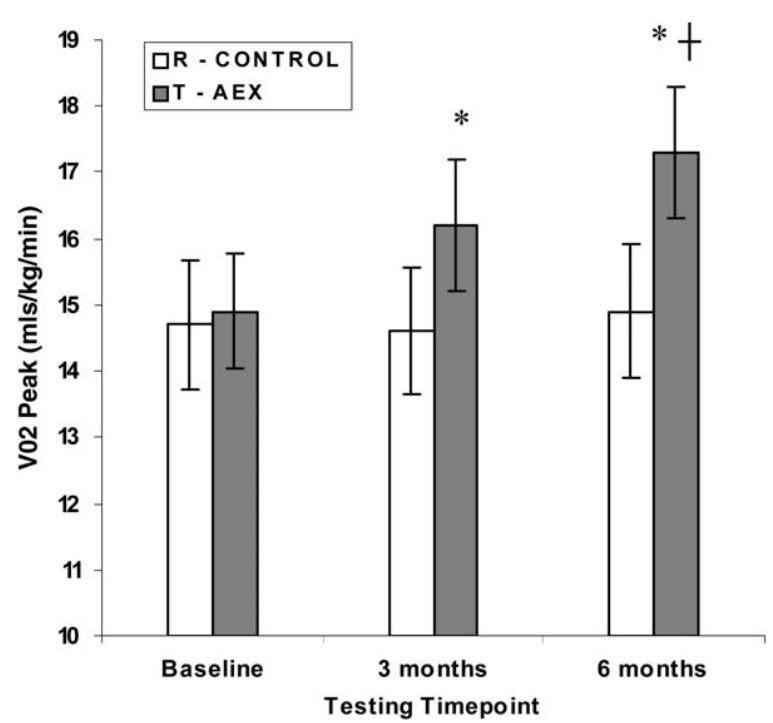

FIG. 5. Progression of improvement in $\mathrm{VO}_{2}$ peak (mean $\pm \mathrm{SE}$ ) over 6 months with progressive treadmill training in chronic hemiparetic stroke patients. $\mathrm{R}=$ conventional rehabilitation (controls); T-AEX = treadmill aerobic exercise. *Differs significantly from baseline $(p<0.05)$; ${ }^{\dagger}$ Significant difference between groups $(p<0.05)$. Reproduced with permission from Stroke (Ref. 35).

Collectively, these results show that the treadmill walking condition improves the symmetry of selected gait and paretic leg muscle activation patterns, and provides evidence that a single training session alters corticospinal excitability to the hemiparetic leg muscles. These findings support a rationale for plasticity studies across treadmill aerobic training interventions in chronic stroke patients.

\section{Time profile for exercise-mediated adaptations}

Few studies have investigated the temporal profile of exercise-mediated adaptations after stroke. Based on studies of exercise rehabilitation in the frail elderly, we studied the profile of fitness and mobility function gains across 6 months of training, ${ }^{35}$ a much longer therapeutic duration than is typical for most stroke rehabilitation programs. Our results show that the time profiles of cardiovascular fitness gains with treadmill exercise training are progressive and nearly equal across the initial 3 months and from the 3rd to the 6th month of training (FIG. 5). There is no evidence of plateau, suggesting that training even beyond 6 months may produce further benefits in peak fitness levels. In addition, treadmill exercise also improves 6-minute walk performance and self-reported indices of functional mobility across 6 months, with greater gains in 6-minute walk occurring within the initial 3 months of training (FIG. 6).

Notably, prospective studies show a plateau in mobility recovery within 3 months after stroke in $95 \%$ of hemiparetic patients receiving conventional rehabilitation care. ${ }^{28}$ Our findings in this randomized study show that treadmill training improves both fitness and mobility function long after conventional rehabilitation care has ended, and that the duration of exercise therapy to optimize these outcomes is at least 6 months. These results support a rationale for long-term exercise after stroke,

FIG. 6. Progression of improvement in 6-minute walk distance (mean \pm $\mathrm{SE})$ over 6 months with progressive treadmill training in chronic hemiparetic stroke patients. $R=$ conventional rehabilitation (controls); T-AEX $=$ treadmill aerobic exercise. *Differs significantly from baseline $(p<0.05)$; †Significant difference between groups $(p<0.05)$. Reproduced with permission from Stroke (Ref. 35).

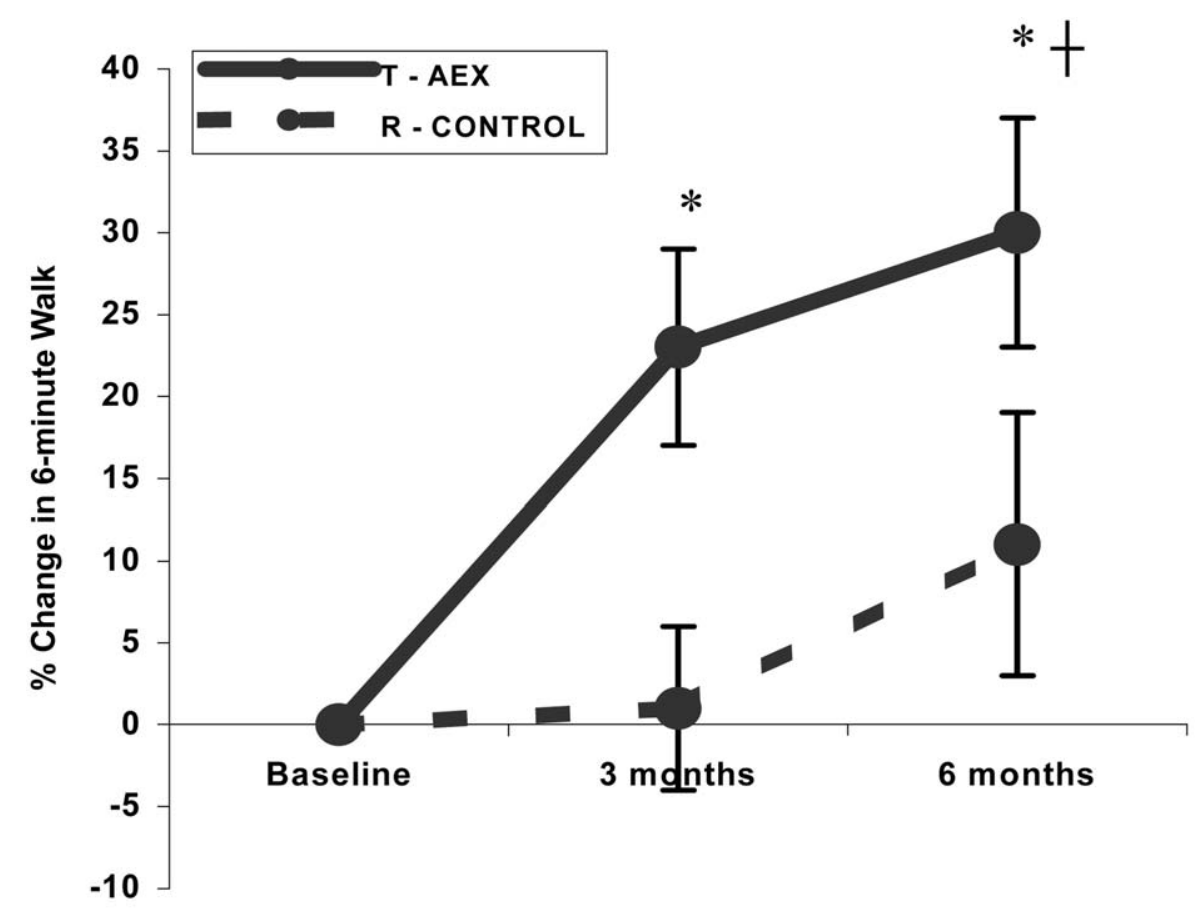

Testing Timepoint 


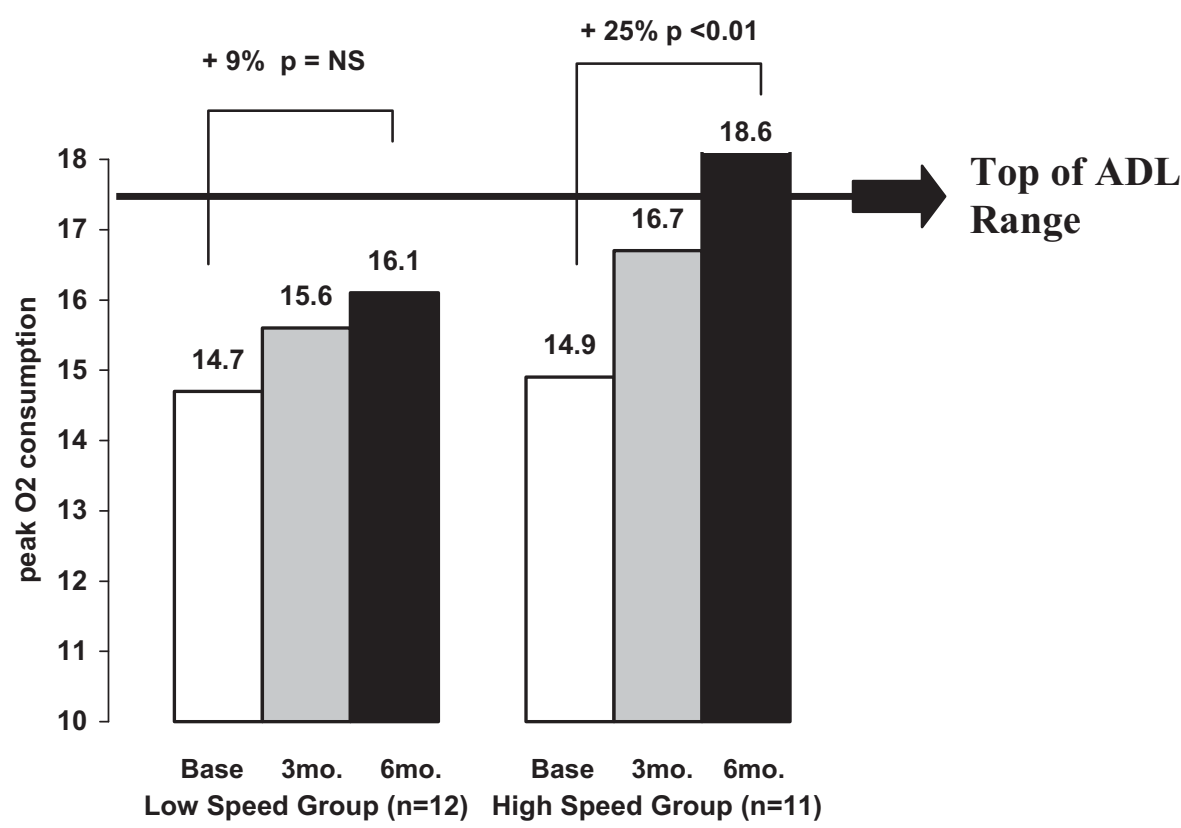

FIG. 7. Effects of differing training speed progressions on adaptation in $\mathrm{VO}_{2}$ peak, in $(\mathrm{mLs} / \mathrm{kg}) / \mathrm{min}$, relative to the upper limits of the $A D L$ over a 6-month intervention period. Adapted with permission from Stroke (Ref. 35).

consistent with public health recommendations in the United States for sustained regular exercise to improve fitness and cardiovascular health for all persons. ${ }^{35}$

\section{Exercise prescription and predictors of outcomes}

An important question is which stroke patients are most likely to benefit from exercise training, and to what extent do specific features of the training regimen and its progression predict treatment outcomes in the domains of fitness and function. We find no clinical or demographic factors that predict a lack of treatment response to treadmill training. Regression analyses show no relationship between the percent gains in either fitness or ambulatory function, and the baseline severity of hemiparetic gait deficits, initial fitness levels $\left(\mathrm{VO}_{2}\right.$ peak), age, or time between the stroke and starting exercise (range 6 months to 10 years). ${ }^{35}$ This promising finding suggests that large numbers of stroke patients may benefit from structured exercise therapy to improve ambulatory function and fitness even years after a stroke.

Specific characteristics of a treadmill training regimen may influence the nature of exercise-mediated adaptation. For example, progression in treadmill training velocity across 6 months predicts gains in $\mathrm{VO}_{2}$ peak $(r=$ $0.43, p<0.05$ ), but not change in 6-minute walk distance $(r=0.17, p=0.46)$. In contrast, the degree of training session duration progression predicts 6-minute walk gains $(r=0.41, p<0.05)$ but not gains in $\mathrm{VO}_{2}$ peak $(r=0.19, p=0.34)$. A median split analysis according to degree of treadmill velocity progression over 6 months reveals that subjects in the upper half (greater velocity progression) experienced larger gains in $\mathrm{VO}_{2}$ peak $(25 \%, n=11, p<0.01)$. Those in the bottom half did not reach a significant within-group fitness gain $(9 \%, n=12, p=\mathrm{NS})$ (FIG. 7). ${ }^{35}$

Cardiovascular and metabolic fitness adaptations after stroke may thus be contingent on advancing training velocity, rather than heart rate reserve (which is the usual standard for defining exercise intensity in non-neurological population). This may have important clinical implications for metabolic risk factor modification and secondary stroke prevention. Post hoc analysis of our treadmill training studies further shows that progression in treadmill training duration across 6 months predicts improvements in 6-minute walk performance, but not change in fitness levels. This raises the possibility that greater task practice with longer training sessions may facilitate locomotor recovery, which is consistent with findings from animal and clinical upper-extremity hemiparesis studies, that task repetition mediates motor learning associated with neuroplasticity. ${ }^{42}$ Further studies are needed to determine whether specific features of the training prescription determine the nature of exercisemediated outcomes after hemiparetic stroke.

\section{SUMMARY AND FUTURE DIRECTIONS}

\section{Rationale for exercise after stroke}

Increasing evidence suggests that cardiovascular deconditioning with associated abnormalities in body composition can propagate disability and worsen risk factor profiles. Numerous studies demonstrate functional aerobic impairment across all phases of stroke recovery with reported fitness levels $40 \%$ to $60 \%$ below age-matched controls. Poor fitness coupled with elevated energy demands of hemiparetic gait result in diminished physio- 
logical fitness reserve that likely limits basic mobility and ADL function.

Poststroke body composition abnormalities that predict poor fitness (including skeletal muscle atrophy and increased fat content, shift to fast myosin heavy chain muscle phenotype, and elevated $\mathrm{TNF} \alpha$ expression) are linked to insulin resistance and are potentially modifiable by exercise. Although insulin resistance and associated cardiovascular comordibities are prevalent after stroke, little is known regarding the mechanisms by which exercise could modify metabolic risk factor profiles in this population. Further studies are needed to define the role of exercise in health promotion and secondary prevention of stroke. Whether exercise training improves ADL profiles and cardiovascular and health outcomes, or can reduce the risk for recurrent stroke, remains unknown.

\section{Effects of exercise on fitness and function}

Randomized studies now show that several exercise modalities can improve fitness after stroke. Gains in $\mathrm{VO}_{2 \text { peak }}$ ranging from $9 \%$ to $23 \%$ are reported across both subacute $(<6$ months) and chronic stroke phases, indicating that exercise produces gains in fitness for individuals with hemiparesis comparable to those seen in those without disabilities. Increasing evidence also suggests that selected exercise modalities improve indices of functional mobility. In particular, some exercise protocols using variants of stepping or walking training show modest gains in walking velocity and endurance, raising the possibility that task-oriented training may facilitate locomotor recovery. Nonetheless, the precise training modalities to facilitate mobility recovery and whether they translate into improved ADL function are unknown. Further studies are needed to identify optimal training modalities to durably improve mobility function and free-living physical activity profiles after stroke.

\section{Dose intensity and timing of exercise}

Conventional rehabilitation is time-delimited within the subacute stroke phase and does not provide adequate aerobic intensity to reverse the profound deconditioning that occurs during aging with the chronic disability of stroke. However, treadmill exercise studies that integrate locomotor learning with progressive aerobic training show gains in fitness and ambulatory function are progressive over 6 months of training, even when initiated years after stroke. Recent studies suggest that higher exercise intensity is crucial to improving cardiovascular fitness, and greater dose in task repetition predicts gains in ambulatory function. These results support a rationale for testing different intensity training programs across longer windows than are typical in conventional rehabilitation care, with the goal of defining exercise prescriptions that effectively mediate motor learning and metabolic adaptations throughout the stroke recovery period.

\section{Conclusions and community translation}

Structured exercise has the potential to improve both cardiovascular fitness and selected functional mobility outcomes in subacute and chronic hemiparetic stroke patients. The potential for exercise models to improve longitudinal rehabilitation and cardiovascular health outcomes is high. However, most research has been conducted in mild to moderately gait-impaired subjects, and the usefulness of many studies for determining the predictors of treatment response is limited by a lack of characterization of exercise intensity and progression, no indication of fidelity to treatment, or limited clinical detail. Progress in the development of community-based models is facilitating the examination of the feasibility and public health value of regular exercise for improving long-term rehabilitation and cardiovascular health outcomes after stroke. Larger randomized studies are needed to generate evidence-based guidelines for the safe and effective exercise of stroke survivors across the spectrum of deficit profiles and recovery phases.

Acknowledgments: This work was supported in part by the University of Maryland Claude D. Pepper Older Americans Independence Center, National Institute on Aging grant number 5-P60-AG12583, National Institute on Aging grant number 5-K01-AG19242, and the Department of Veterans Affairs and Veterans Affairs Medical Center, Baltimore, Geriatric Research, Education and Clinical Center (GRECC).

\section{REFERENCES}

1. Corcoran PJ, Jebsen RH, Brengelmann GL, Simons BC. Effects of plastic and metal leg braces on speed and energy cost of hemiparetic ambulation. Arch Phys Med Rehabil 1970;51:69-77.

2. Gersten JW, Orr W. External work of walking in hemiparetic patients. Scand J Rehabil Med 1971;3:85-88.

3. Fisher SV, Gullickson G Jr. Energy cost of ambulation in health and disability: a literature review. Arch Phys Med Rehabil 1978; 59:124-133.

4. Olney SJ, Monga TN, Costigan PA. Mechanical energy of walking of stroke patients. Arch Phys Med Rehabil 1986;67:92-98.

5. Mol VJ, Baker CA. Activity intolerance in the geriatric stroke patient. Rehabil Nurs 1991;16:337-343.

6. McArdle WD, Katch KF, Katch VL. Energy nutrition and human performance. Baltimore: Williams and Wilkins; 1996.

7. Ivey FM, Macko RF, Ryan AS, Hafer-Macko CE. Cardiovascular health and fitness after stroke. Top Stroke Rehabil 2005;12:1-16.

8. American College of Sports Medicine. ACSM's guidelines for exercise testing and prescription. 6th ed. Baltimore: Lippincott Williams and Wilkins; 2000.

9. Bruce RA, Kusumi F, Hosmer D. Maximal oxygen intake and nomographic assessment of functional aerobic impairment in cardiovascular disease. Am Heart J 1973;85:546-562.

10. Jette M, Sidney K, Blumchen G. Metabolic equivalents (METS) in exercise testing, exercise prescription, and evaluation of functional capacity. Clin Cardiol 1990;13:555-565.

11. Ainsworth BE, Haskell WL, Whitt MC, et al. Compendium of physical activities: an update of activity codes and MET intensities. Med Sci Sports Exerc 2000;32(9 Suppl):S498-S504.

12. Ryan AS, Dobrovolny CL, Smith GV, Silver KH, Macko RF. Hemiparetic muscle atrophy and increased intramuscular fat in stroke patients. Arch Phys Med Rehabil 2002;83:1703-1707.

13. De Deyne PG, Hafer-Macko CE, Ivey FM, Ryan A, Macko RF. Muscle molecular phenotype after stroke is associated with gait speed. Muscle Nerve 2004;30:209-215. 
14. Kernan WN, Inzucchi SE, Viscoli CM, et al. Impaired insulin sensitivity among nondiabetic patients with a recent TIA or ischemic stroke. Neurology 2003;60:1447-1451.

15. Ryan AS, Dobrovolny CL, Silver KH, Smith GV, Macko RF. Cardiovascular fitness after stroke: role of muscle mass and gait deficit severity. J Stroke Cerebrovasc Dis 2000;9:185-191.

16. Landin S, Hagenfeldt L, Saltin B, Wahren J. Muscle metabolism during exercise in hemiparetic patients. Clin Sci Mol Med 1977; 53:257-269.

17. Daugaard JR, Richter EA. Relationship between muscle fibre composition, glucose transporter protein 4 and exercise training: possible consequences in non-insulin-dependent diabetes mellitus. Acta Physiol Scand 2001;171:267-276.

18. Hunter RB, Stevenson E, Koncarevic A, et al. Activation of an alternative NF- $\kappa$ B pathway in skeletal muscle during disuse atrophy. FASEB J 2002;16:529-538.

19. Greiwe J, Cheng B, Rubin DC. Resistance exercise decreases skeletal muscle tumor necrosis factor alpha in frail elderly humans. FASEB J 2001;15:475-482.

20. Saghizadeh M, Ong JM, Garvey WT, Henry RR, Kern PA. The expression of $\mathrm{TNF} \alpha$ by human muscle: relationship to insulin resistance. J Clin Invest 1996;97:1111-1116.

21. Borst SE, Lee Y, Conover CF, Shek EW, Bagby GJ. Neutralization of tumor necrosis factor- $\alpha$ reverses insulin resistance in skeletal muscle but not adipose tissue. Am J Physiol Endocrinol Metab 2004;287:E934-E938.

22. Hafer-Macko CE, Yu S, Ryan AS, Ivey FM, Macko RF. Elevated tumor necrosis factor- $\alpha$ in skeletal muscle after stroke. Stroke 2005;36:2021-2023.

23. Ivey FM, Gardner AW, Dobrovolny CL, Macko RF. Unilateral impairment of leg blood flow in chronic stroke patients. Cerebrovasc Dis 2004;18:283-289.

24. Ivey FM, Ryan AS, Hafer-Macko CE, et al. High prevalence of abnormal glucose metabolism and poor sensitivity of fasting plasma glucose in the chronic phase of stroke. Cerebrovasc Dis 2006;22:368-371.

25. Gresham GE; Post-Stroke Rehabilitation Guideline Panel. Poststroke rehabilitation: clinical practice guideline no. 16. DHHS Publication AHCPR 95-0662. Washington, DC: U.S Government Printing Office; 1995.

26. MacKay-Lyons MJ, Makrides L. Cardiovascular stress during a contemporary stroke rehabilitation program: is the intensity adequate to induce a training effect? Arch Phys Med Rehabil 2002; 83:1378-1383.

27. Duncan P, Studenski S, Richards L, et al. Randomized clinical trial of therapeutic exercise in subacute stroke. Stroke 2003;34:21732180.

28. Jorgensen HS, Nakayama H, Raaschou HO, Olsen TS. Recovery of walking function in stroke patients: the Copenhagen Stroke Study. Arch Phys Med Rehabil 1995;76:27-32.

29. Wade DT, Hewer RL. Functional abilities after stroke: measurement, natural history and prognosis. J Neurol Neurosurg Psychiatry 1987;50:177-182.

30. Potempa K, Lopez M, Braun LT, Szidon JP, Fogg L, Tincknell T. Physiological outcomes of aerobic exercise training in hemiparetic stroke patients. Stroke 1995;26:101-105.

31. Rimmer JH, Riley B, Creviston T, Nicola T. Exercise training in a predominantly African-American group of stroke survivors. Med Sci Sports Exerc 2000;32:1990-1996.

32. Chu KS, Eng JJ, Dawson AS, Harris JE, Oakaplan A, Gylfadottir
S. Water-based exercise for cardiovascular fitness in people with chronic stroke: a randomized controlled trial. Arch Phys Med Rehabil 2004;85:870-874.

33. Pang MY, Harris JE, Eng JJ. A community-based upper-extremity group exercise program improves motor function and performance of functional activities in chronic stroke: a randomized controlled trial. Arch Phys Med Rehabil 2006;87:1-9.

34. Pang MY, Eng JJ, Dawson AS, McKay HA, Harris JE. A community-based fitness and mobility exercise program for older adults with chronic stroke: a randomized, controlled trial. J Am Geriatr Soc 2005;53:1667-1674.

35. Macko RF, Ivey FM, Forrester LW, et al. Treadmill exercise rehabilitation improves ambulatory function and cardiovascular fitness in patients with chronic stroke: a randomized, controlled trial. Stroke 2005;36:2206-2211.

36. Macko RF, Katzel LI, Yataco A, et al. Low-velocity graded treadmill stress testing in hemiparetic stroke patients. Stroke 1997;28: 988-992.

37. Macko RF, DeSouza CA, Tretter LD, et al. Treadmill aerobic exercise training reduces the energy expenditure and cardiovascular demands of hemiparetic gait in chronic stroke patients: a preliminary report. Stroke 1997;28:326-330.

38. Macko RF, Smith GV, Dobrovolny CL, Sorkin JD, Goldberg AP, Silver KH. Treadmill training improves fitness reserve in chronic stroke patients. Arch Phys Med Rehabil 2001;82:879-884.

39. Harris-Love ML, Forrester LW, Macko RF, Silver KH, Smith GV. Hemiparetic gait parameters in overground versus treadmill walking. Neurorehabil Neural Repair 2001;15:105-112.

40. Harris-Love ML, Forrester LW, Macko RF, Smith GV. Hemiparetic vastus lateralis activation patterns in overground compared with treadmill walking. Neurorehabilitation and Neural Repair 2002;16:379.

41. Forrester LW, Hanley DF, Macko RF. Effects of treadmill exercise on transcranial magnetic stimulation-induced excitability to quadriceps after stroke. Arch Phys Med Rehabil 2006;87: 229-234.

42. Nudo RJ, Wise BM, SiFuentes F, Millikin GW. Neural substrates for the effects of rehabilitative training on motor recovery after ischemic infarct. Science 1996;272:1791-1794.

43. Hesse S, Bertelt C, Schaffrin A, Malezic M, Mauritz KH. Restoration of gait in nonambulatory hemiparetic patients by treadmill training with partial body-weight support. Arch Phys Med Rehabil 1994;75:1087-1093.

44. Duncan P, Richards L, Wallace D, Stoker-Yates J, Pohl P, Luchies C, Ogle A, Studenski S. A randomized, controlled pilot study of a home-based exercise program for individuals with mild and moderate stroke. Stroke 1998;29:2055-2060.

45. Teixeira-Salmela LF, Olney SJ, Nadeau S, Brouwer B. Muscle strengthening and physical conditioning to reduce impairment and disability in chronic stroke survivors. Arch Phys Med Rehabil 1999;80:1211-1218.

46. Katz-Leurer M, Carmeli E, Shochina M. The effect of early aerobic training on independence six months post stroke. Clin Rehabil 2003;17:735-741.

47. Eng JJ, Chu KS, Kim CM, Dawson AS, Carswell A, Hepburn KE. A community-based group exercise program for persons with chronic stroke. Med Sci Sports Exerc 2003;35:1271-1278.

48. Eich HJ, Mach H, Werner C, Hesse S. Aerobic treadmill plus Bobath walking training improves walking in subacute stroke: a randomized controlled trial. Clin Rehabil 2004;18:640-651. 